\title{
Ultrasound-assisted Extraction of Polyphenols from Red-grape (Vitis vinifera) Residues
}

\author{
Usaquén-Castro, X.; Martínez-Rubio, M., Aya-Baquero, H., and González-Martínez, G*. \\ Engineering Faculty, Universidad de La Sabana, Chía, Colombia. \\ Gerardo.Gonzalez@unisabana.edu.co
}

\begin{abstract}
Red-grape (Vitis vinifera) residues contain large amounts of polyphenols, especially anthocyanins which act as antioxidants. Red-grape seeds and peel were separated from the pulp and exposed to pre-treatments with ultrasound at 35kHz over 15, 30, 45, 60, 75 y 90min as an alternative to improve the level of polyphenols extraction. Right after the pre-treatment with ultrasound, samples were subjected to an extraction operation by methanol/water $(96 \%$ $v / v)$ at $60^{\circ} \mathrm{C}$ over $90 \mathrm{~min}$, according to similar conditions previously optimized by Pinelo, $M$ (2004). Both total extractive yield (dry basis) and total polyphenols content were determined for all the extracts obtained from the treated samples, and compared against an extract obtained from a non treated sample. Results showed that at the studied frequency $(35 \mathrm{kHz})$, there is a significant effect $(\alpha=0.05)$ of the ultrasound exposure time on both total extractive yield and total polyphenols content. When compared to non treated samples, the exposure to ultrasound at 45min and above showed to significantly $(\alpha=0.05)$ improve the extraction operation by increasing in more than $25 \%$ the total extractive yield, except at $75 \mathrm{~min}$. Results also showed that ultrasound exposure of the samples at 45, 75 and 90min significantly increased $(\alpha=0.05)$ the total polyphenols content of the extracts in about 65,50 and $140 \%$, respectively. The effect of ultrasound on the antioxidant capacity of the extracts was also evaluated. Results indicated that ultrasound at $35 \mathrm{kHz}$ decreases the antioxidant capacity of the extracts in about $50 \%$.
\end{abstract}

Key words: Polyphenols, antioxidant capacity, ultrasound-assisted extraction, Red-grape byproducts.

\section{INTRODUCTION}

Wine industry generates large amount of residues, whose elimination usually supposes a management problem. Approximately $15-20 \mathrm{~kg}$ of solid residues (bagasse) are obtained for each $100 \mathrm{~kg}$ of grapes that are processed to produce alcoholic beverages (Alvarez, 1991). In Spain for example, about $500 \times 10^{3}$ tons of red-grape residues were produced during year 2003 (Prodanov and Cobo, 2004), increasing up to $800 \times 10^{3}$ tons during year 2004 (Prodanov et al., 2005). However, it has been shown that these residues represent an important source of compounds such as polyphenols, especially anthocyanins which act as antioxidants. Some studies have reported that red-grape residues contain about $0.09-0.35 \%$ polyphenols (Medina et al., 2002; Pinelo, 2004; Cieślik et al., 2006). During the last years the interest in these components has increase due to their relationship to human health. Several studies have proved that antioxidants such as polyphenols help the body to protect against deteriorative reactions and diseases. Gutiérrez (2002) demonstrated that polyphenols may have a protective effect against cardiovascular diseases or even some kinds of cancer. Additionally, Shi et al. (2003) stated that extracted polyphenols from grape help the body to protect against damage produced by sun shines, to improve vision and blood circulation, to reduce LDL (Low Density Lipoproteins) oxidation and the occurrence of coronary diseases. Medina et al. (2002) indicated that polyphenolic extracts from grape and apple present a high antioxidant activity 
of natural fats and oils (fish oils). Beyond the benefits for human health, polyphenols have a wide range of applications in the food industry as colorants, functional additives in beverages, dairy products, candies, bakery and cereals. Natural antioxidants for example can be used to increase shelf life of food by preventing lipid peroxidation and protecting oxidative damage (Moure et al., 2001). Thus, there is no doubt that recovering polyphenols from agro-industrial residues might represent an economically sustainable strategy, not only for diminishing the environmental impact of industrial wastes by producing zero emissions but for generating greater added value by obtaining new products of great interest for the chemical, pharmaceutical and food industries (Prodanov et al., 2004). Many companies have reported great benefices due to production and selling of polyphenols. That is the case of Frost \& Sullivan, an European Company that registered incomes for about $€ 77.88$ million in 2003 just for polyphenols European market (Anderson, N., 2004). Polyphenols are commonly obtained by extraction with organic solvents such as methanol, ethanol and acetone (Cork and Krockenberger, 1991; Escribano-Bailón et al, 1992; Vernhet et al., 1996; Fuleki and da Silva, 1997; Kallithraka et al., 1997) at different temperatures and using times that may range from few minutes to several hours. In 2004 Pinelo optimized operating conditions to perform the extraction of polyphenols from grapes. His results, which were based upon total yield versus antioxidant capacity of the extracts, showed that the best performance is achieved when using mixtures of methanol-water (solid-liquid relation of $1: 1$ ) at $50^{\circ} \mathrm{C}$ over $90 \mathrm{~min}$ contact. However, efficiency of extraction strongly depends on operative conditions and the current challenge is to improve the total yield by introducing previous steps to increase the mass transfer rate during the operation.

During the last few years, ultrasound-assisted technology using high intensity ultrasound waves has caught the attention of food scientists due to its promising effects on biological systems which can be taken as an advantage for product modification and process improvement. High intensity ultrasound waves produce intense pressure, shear and temperature gradients within the material leading to a physical disruption of its structure (McClements, 1995). Both biological cell walls and cell membranes are disrupted due to the cavitation (implosion of gas bubbles within the material) caused by considerable changes in temperature and pressure $\left(5500^{\circ} \mathrm{C}\right.$ and $50 \mathrm{MPa}$, respectively) during a very short period of time (Sala et al., 1995; Knorr, 2004,). Additionally, cavitation causes particle size reduction which increases the surface area in contact between the solid and the liquid phase. Therefore, ultrasound induces a better penetration of solvent into cellular materials which improves mass transport rates within the tissue and facilitates the transfer of components from the cell into the solvent leading to the enhancement of the extraction operation (Mason, et al., 1996; Wang and Weller, 2006). Studies of ultrasound application during osmotic dehydration of apples have demonstrated that there is an increase of mass transfer after applying ultrasound waves on samples (Simal et al., 1998). It has also been demonstrated that ultrasonic waves improve the extraction level of calcium $(\mathrm{Ca})$, potassium $(\mathrm{K})$ and magnesium $(\mathrm{Mg})$ from in vitro citrus culture (Arruda et al., 2003), the extraction level of polyphenols from tobacco (Gu et al., 2005) and the extraction level of polyphenols from strawberries (Herrera and Luque de Castro, 2005). Wang and Weller (2006) cited several studies that provide evidences about benefits and potential applications of ultrasound-assisted extraction of bioactive compounds from plants.

According to above, the present study aims to evaluate the effect of high intensity ultrasound exposure time on both the yield and the antioxidant activity of polyphenols extracted from red-grape residues. 


\section{MATERIALS AND METHODS}

\section{Sample Preparation and characterization}

Fresh red-grapes were bought at the local market and immediately used to obtain the solid residues. Red-grapes were washed by immersion in cold water and then crushed for about $1 \mathrm{~min}$ in a Black \& Decker food processor. Solid material was carefully separated from the liquid by passing the suspension through a piece of gauze and then squeezing it up to obtain the solids as dry as possible. The obtained solid residue was homogenized and equally divided into samples to perform the ultrasound treatments.

Initial moisture content of the solid residues, as well as total extractive yield (TEY) and total polyphenols content of the extracts (TPC) were determined before the ultrasound treatment and used as control parameters to establish the effects of the exposure time. Moisture content of the samples was measured by standard method at $105^{\circ} \mathrm{C}$ and triplicates were run for each sample. Both total extractive yield (TEY) and total polyphenols content of the extracts (TPC) were determined after the extraction by Soxhlet method according to Pinelo (2004), increasing contact time and operation temperature up to $120 \mathrm{~min}$ and $60^{\circ} \mathrm{C}$, respectively.

\section{Determination of Total Extractive Yield (T.E.Y)}

After Soxhlet extraction, dry extracts were obtained by evaporating the solvent at room temperature and the TEY was determined by weight differences. Result are expressed as a percentage (g total extract/ 100g dry solid)

\section{Determination of Total Polyphenols Content (T.P.C)}

Total Polyphenols Content of the extracts was determined by the Folin-Ciocalteu Method, as described and modified by Singleton and Rossi (1965) and Kaur and Kapoor (2002). Aliquots of $100 \mu 1$ of extract were dissolved in $6 \mathrm{ml}$ of distilled water, and added by $0.5 \mathrm{ml}$ of FolinCiocalteu reagent and $1.5 \mathrm{ml}$ of $20 \%(\mathrm{w} / \mathrm{v})$ sodium carbonate solution. Distilled water to a total volume of $10 \mathrm{ml}$ was added to the resulting solution and then taken to rest in darkness over about $1 \mathrm{~h}$. After resting time, absorbance of the samples was measured at $450 \mathrm{~nm}$ in a CARY 100 CONC spectrophotometer. TPC content of extracts was determined as catechol equivalents by using a calibration curve of catechol solutions of known concentration. Results are expressed as a percentage (g polyphenols/100g dry solid).

\section{Determination of Ultrasound Exposure Times}

In order to establish the minimum exposure time required to obtain any differences in the TPC of the extracts, preliminary experiments were performed by quintuplets. Samples of fresh grape-bagasse $(10 \pm 0.001 \mathrm{~g})$ were exposed to ultrasound at a constant frequency of $35 \mathrm{kHz}$ over 5, 10, 15, 20 and $25 \mathrm{~min}$. After the chosen exposure time samples were taken out of ultrasound bath and subjected to extraction as described above. Then both the TEY and the TPC of the extracts were determined as described before and compared against values from non-treated samples.

\section{Ultrasound Treatments}

Samples of fresh grape-bagasse $(10 \pm 0.001 \mathrm{~g})$ were added by $20 \mathrm{ml}$ of solvent, placed into low density polyethylene bags and sealed as hermetically as possible. Then, bags were immersed in an ultrasound bath ELMA LC30H $(2.75 \mathrm{~L}$ capacity and $240 \mathrm{~W}$ of incoming power) and subjected to ultrasound treatments at a constant frequency of $35 \mathrm{kHz}$ over 15, 30, 45, 60, 75 and $90 \mathrm{~min}$. After the chosen exposure time, samples were taken out of ultrasound bath and 
subjected to extraction as described above. Five (5) replicates for each treatment were carried out.

\section{Determination of Antioxidant Activity (AA) of the Extracts}

Antioxidant activity (AA) was determined for the extracts obtained from samples exposed to ultrasound over 45 and $90 \mathrm{~min}$, and then compared against the activity of extracts obtained from no-treated samples. AA was determined according to the $\beta$-carotene degradation method as described by Moure et al. (2001), Kaur and Kapoor (2002), and Pérez et al. (2003). This method is based upon comparison of normal degradation velocity of a $\beta$-carotene emulsion against degradation velocity of the same emulsion in presence of the antioxidant extract. To measure the degradation velocity, absorbance of the emulsions was measured at $470 \mathrm{~nm}$ over different times of reaction. AA was expressed as the percentage of inhibition (\%) of the oxidative reaction that is achieved due to the presence of the extract, according to the following equation.

$$
\mathrm{AA}(\%)=\frac{\mathrm{CDv}-\mathrm{SDv}}{\mathrm{CDv}} \times 100
$$

where: $\mathrm{CDv}$ corresponds to degradation velocity of the control emulsion, and SDv corresponds to degradation velocity of the sample to be evaluated. Both the degradation velocity of the sample and the degradation velocity of the control were calculated by lineal regression of the absorbance data against degradation time (in seconds).

\section{Statistical Analysis}

Statistical evaluation was performed using analysis of variance (ANOVA) by SPSS software 13.0 for Windows, followed by Duncan and Tukey pair tests. The complete analysis has a 0.05 significance level $(\alpha=0.05)$.

\section{RESULTS AND DISCUSSION}

As showed in Figures 1 and 2, values of Total Polyphenols Content (TPC) and Total Extractive Yield (TEY) of control samples (non-treated by ultrasound) agreed with the values previously reported by other authors, which are $0.09-0.35 \%$ and $10-15 \%$, respectively (Medina et al., 2002; Pinelo, 2004; Cieślik et al., 2006). Thus, these results validate the comparison of sonicated samples against the controls that were utilized in the preset study. It is important to stand out that similar studies (Pinelo, 2004; Louli et al., 2004) reported TEY from red-grape residues between 12.3 and $14.9 \%$, which are a bit higher from the values reported for control samples in the present study. However, these differences may correspond to differences in grape varieties or perhaps due to differences in the initial moisture content. Further studies involving the effect of other factors such as variety and moisture content must be done in order to probe this hypothesis.

\section{Determination of Ultrasound Exposure Times}

Figure 1 shows the TPC of extracts obtained from preliminary experiments. Results showed there are not significant differences $(\alpha=0.05)$ on polyphenols content of the extracts for all the studied ultrasound exposure times. According to these results it is evident that, at the studied frequency, ultrasound exposure times lower than $25 \mathrm{~min}$ do not cause any effect on polyphenols extraction. Therefore, ultrasound treatments should be carried out at higher exposure times. 


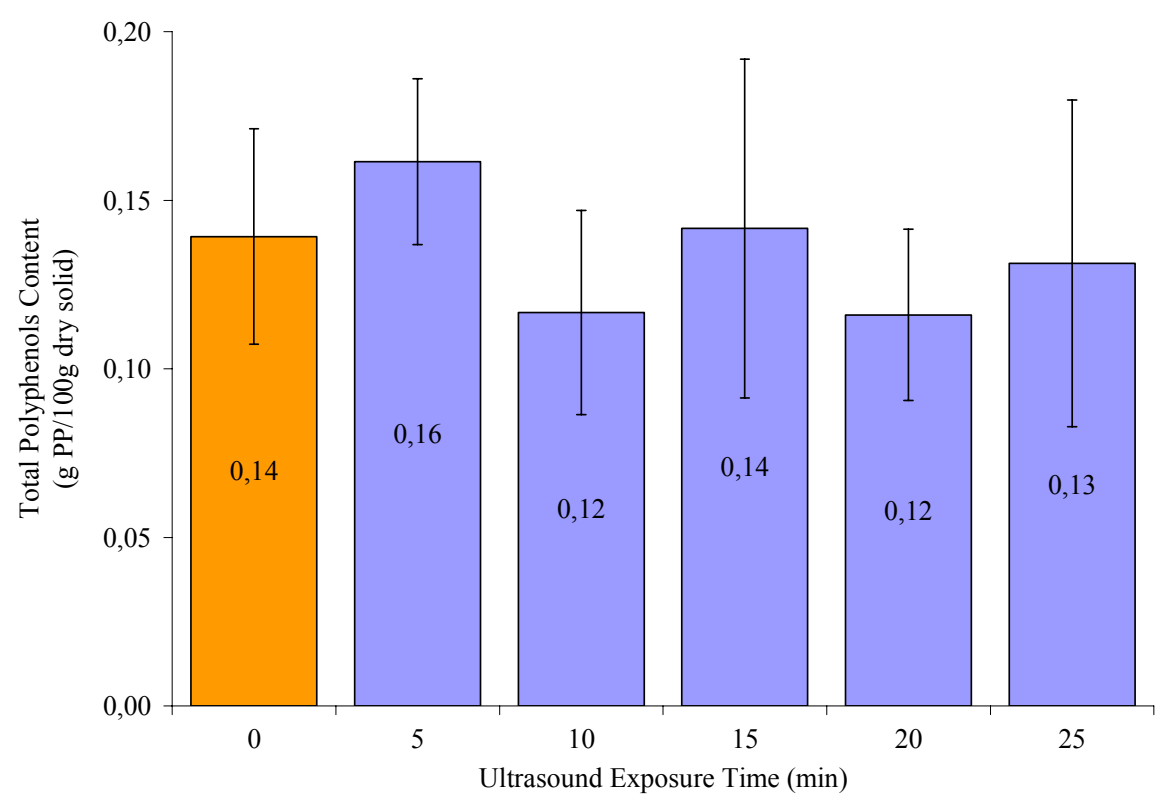

Figure 1. Total Polyphenols Content (TPC) of the extracts obtained from preliminary experiments. Zero ultrasound exposure time corresponds to the control sample (non-exposed to ultrasound).Values correspond to the average of five (5) replicates.

\section{Effect of Ultrasound Exposure Time on the Total Extractive Yield (TEY)}

As shown in Figure 2, at the studied frequency and for all the evaluated exposure times, the use of ultrasound causes an increase on the extraction of methanol soluble components from red-grape residues. However, significant effects $(\alpha=0.05)$ only exists at exposure times of 45 , 60 y $90 \mathrm{~min}$, being the best performance at $90 \mathrm{~min}$ when extraction increases up to $37.5 \%$ (Figure 3). In any case, results showed there is a clear enhancement of the TEY obtained from red-grape residues due to ultrasound (Figure 3). Results of TEY at $75 \mathrm{~min}$ could be interpreted as a decreasing on the extraction level due to some kind of collapsing of the vegetal structure. However, this interpretation is discarded taking into account both the increasing of TEY at $90 \mathrm{~min}$ and the high deviation of data at $75 \mathrm{~min}$ that make this result not statistically reliable.

\section{Effect of Ultrasound Exposure Time on Total Polyphenols Content (TPC) of the Extracts}

Figure 4 shows the effect of ultrasound exposure time on the TPC of the extracts obtained from red-grape residues. Results showed TPC is affected in a similar way to TEY, which endorses preliminary results demonstrating that before $30 \mathrm{~min}$ of treatment with ultrasound at $35 \mathrm{kHz}$, there are not significant effects $(\alpha=0.05)$ on TPC of the extracts. Significant differences $(\alpha=0.05)$ were found at 45,75 and $90 \mathrm{~min}$ of ultrasound exposure when compared against control samples. As showed in Figure 5, TPC of the extracts is enhanced by ultrasound treatment, especially at 45 and $90 \mathrm{~min}$ of exposure where extraction increased 64.9, and $142.0 \%$, respectively. Considering that polyphenols are located into the cytoplasm of the cells, it is clear that ultrasound leads to a kind of tissue permeabilization by the disruption of important cellular structures such as cell walls and cell membranes, which are of great importance for mass transfer control. Some studies have shown that, in contrast to conventional extractions, plant extracts diffuse across cell walls due to ultrasound, causing cell rupture over a shorter period (Chemat et al., 2004; Li et al., 2004; Toma et al., 2001; Vinatoru et al., 1999). Wang and Weller (2006) cited that scanning electron micrographs (SEM) have provided evidence of the mechanical effects of ultrasound, mainly shown by the destruction of cell walls and release of cell contents. Our results also agree with some other 
authors (Minami, 1996; Simal et al., 1998; Nascentes et al.,2001; Yebra and Moreno, 2002; Arruda et al., 2003; Banjoo and Nelson, 2005; Gu et al., 2005; and Herrera and Luque de Castro, 2005), who have stated that ultrasound increases the extraction levels not only of polyphenols but ions $(\mathrm{Cu}, \mathrm{Fe}, \mathrm{K}, \mathrm{Mg} \mathrm{Mn}, \mathrm{Pb}, \mathrm{Se}, \mathrm{Zn})$ and other compounds such as polycyclic aromatic hydrocarbons and water that are present in different biological materials such as citric cultures, seafood, tobacco, strawberries, lettuce, cabbage and apples.

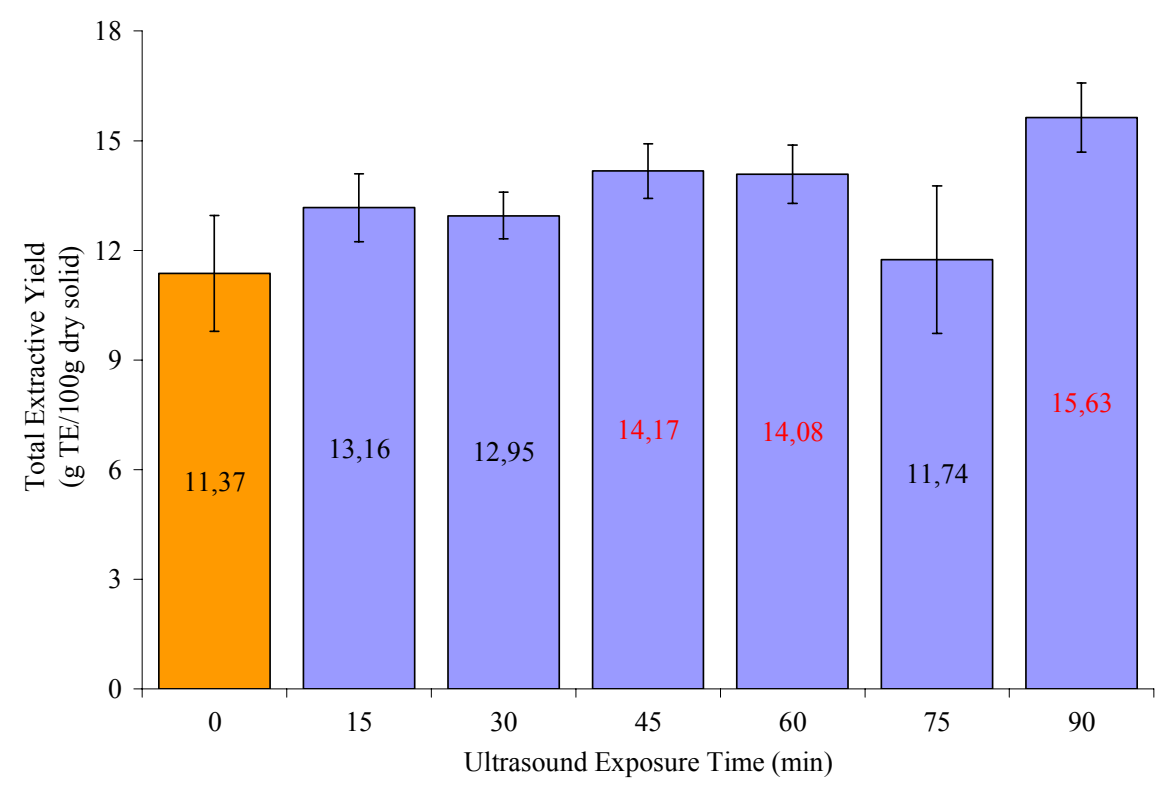

Figure 2. Effect of ultrasound exposure time on the Total Extractive Yield (TEY) obtained from redgrape residues. Zero ultrasound exposure time corresponds to the control sample (non-exposed to ultrasound). Values correspond to the average of five (5) replicates. Red values show treatments that are significantly different $(\alpha=0.05)$ from the control.

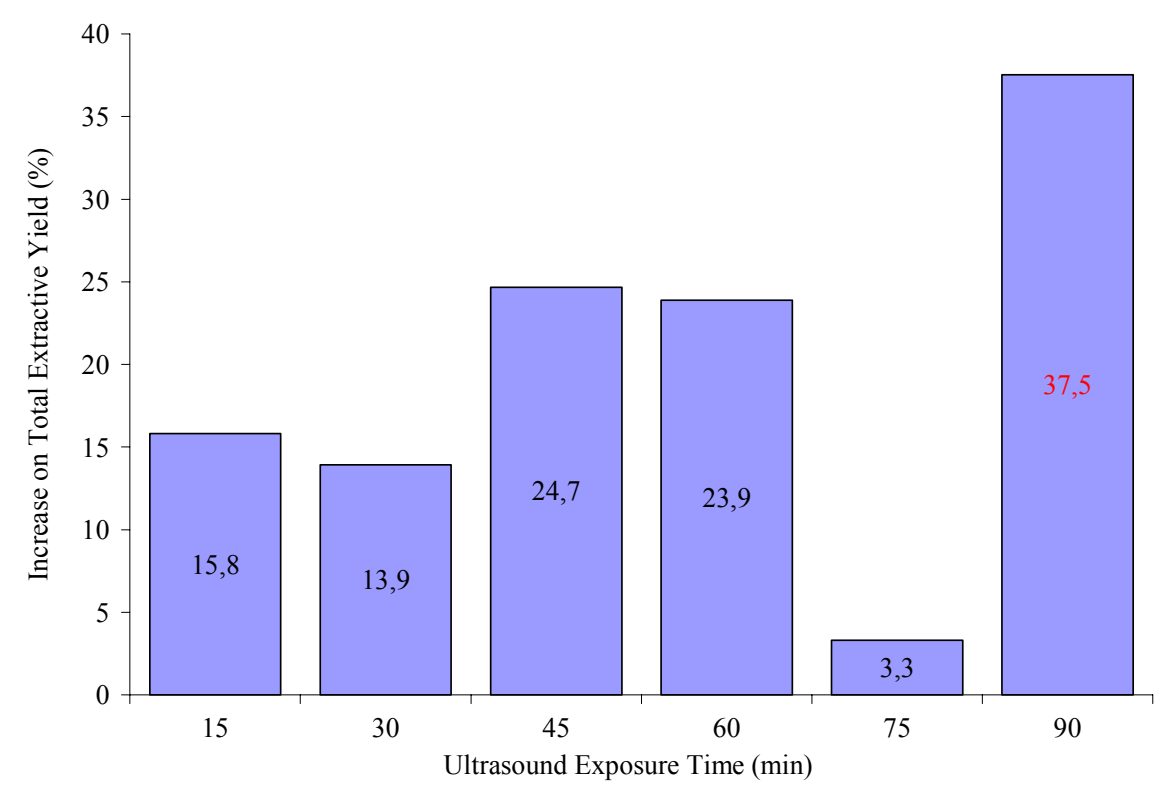

Figure 3. Enhancement of the Total Extractive Yield (TEY) obtained from red-grape residues. Values correspond to Total Extractive Yield differences between sonicated samples (TEYSS) and control samples $\left(T E Y_{C S}\right)$, divided by the value of $T E Y_{C S}\left(T E Y_{S S} T E Y_{C S} T T E Y_{C S}\right)$ 


\section{Effect of Ultrasound on the Antioxidant Activity of Extracts}

As mentioned before, antioxidant activity was only measure for the extracts obtained from red-grape residues exposed to ultrasound over 45 and 90min which where the ones that showed the highest TEY and TPC values. Results showed that, at the studied frequency and exposure times, ultrasound reduces the oxidative inhibition capacity of the extracts in about $50 \%$ when compared to a control extract obtained from non sonicated samples (Figure 6). There are neither evidences nor previous studies that show or explain the effect of ultrasounds on the antioxidant activity of phenolic compounds. Moure et al. (2001) found that antioxidant activity of phenolic compounds depends on many factors such as growing conditions and quality of the original plant (geographic location, weather conditions, etc.), extraction and purification methods (kind and polarity of solvents, extraction conditions, etc.), and even the method used to determine the antioxidant activity. In a more recent study, Medina et al. (2002) reported that non purified extracts from grape bagasse, with a high content of glycoside compounds concentration, were not efficient whilst purified fractions were able to delay oxidative rancidity in oils and emulsions. These results agree with Louli et al. (2004) who stated that in order to improve the antioxidant activity, it is necessary to purify the obtained extract by removing all inert and undesirable components.

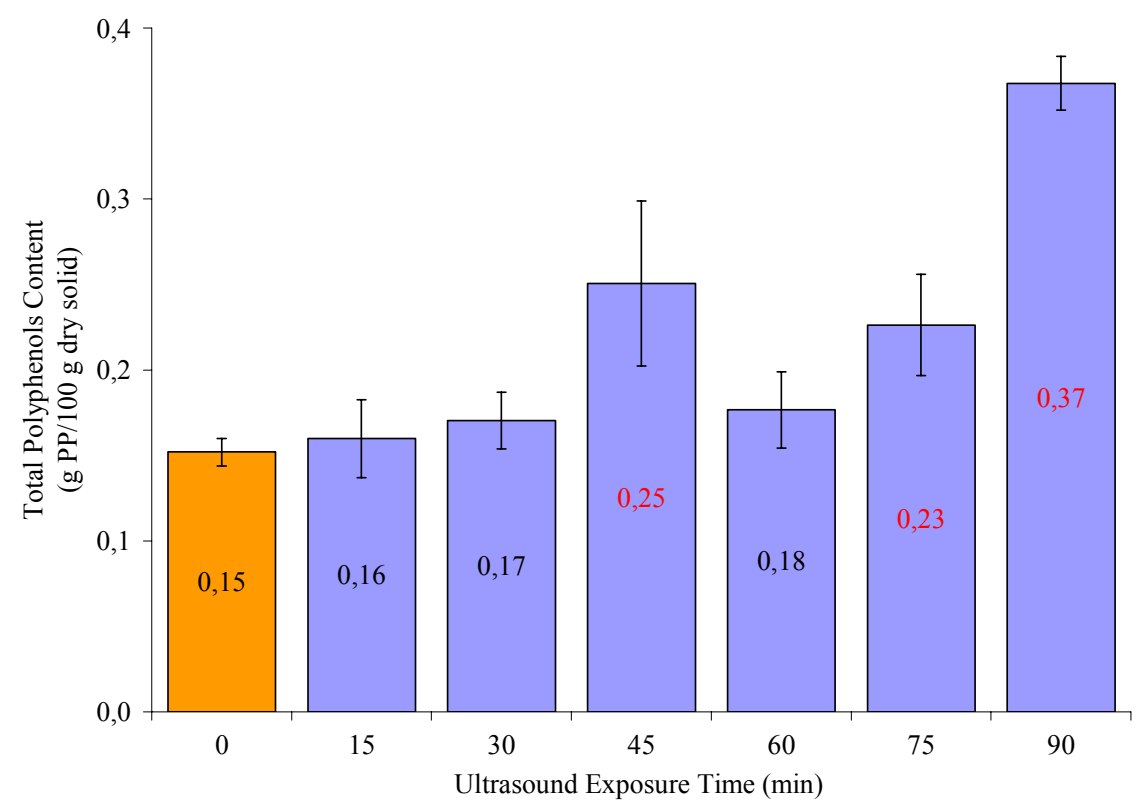

Figure 4. Effect of ultrasound exposure time on the Total Polyphenols Content (TPC) of the extracts obtained from red-grape residues. Zero ultrasound exposure time corresponds to the control sample (non-exposed to ultrasound). Values correspond to the average of five (5) replicates. Red values show treatments that are significantly different $(\alpha=0.05)$ from the control. 


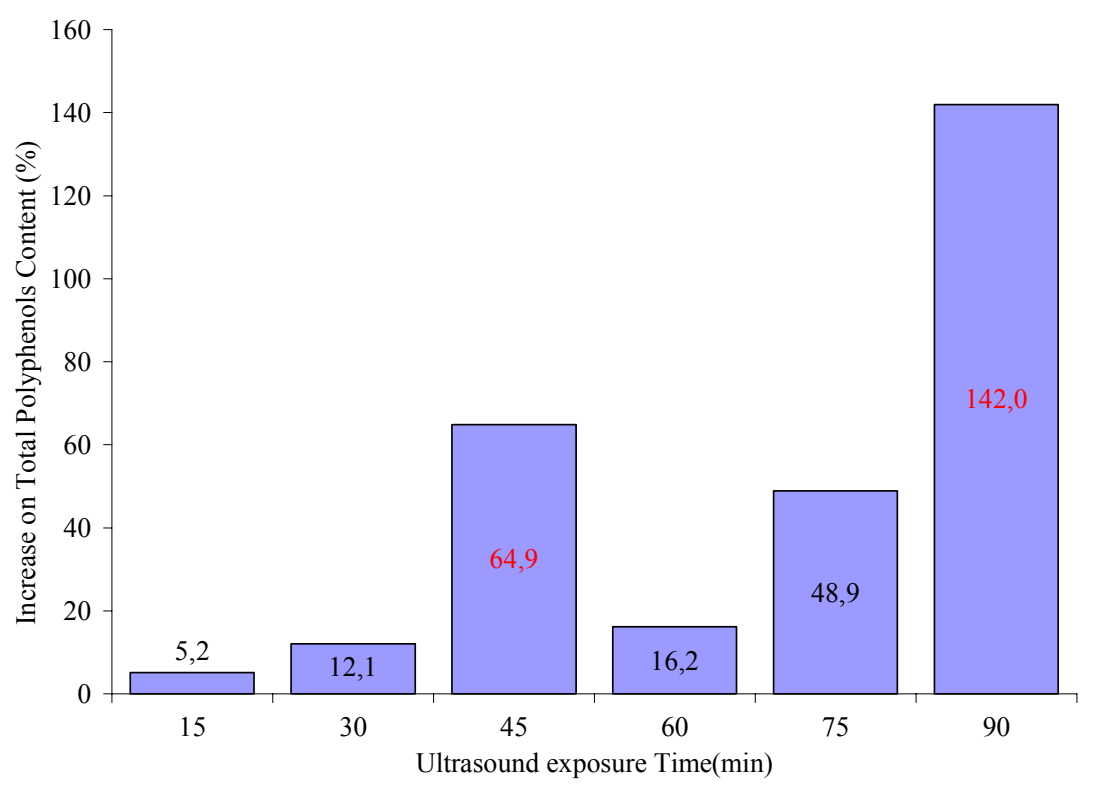

Figure 5. Enhancement of Total Polyphenols Content (TPC) of the extracts obtained from red-grape residues. Values correspond to Total Polyphenols Content differences between sonicated samples $\left(T P C_{S S}\right)$ and control samples $\left(T P C_{C S}\right)$, divided by the value of $T P C_{C S}\left(T P C_{S S}-T P C_{C S} / T P C_{C S}\right)$

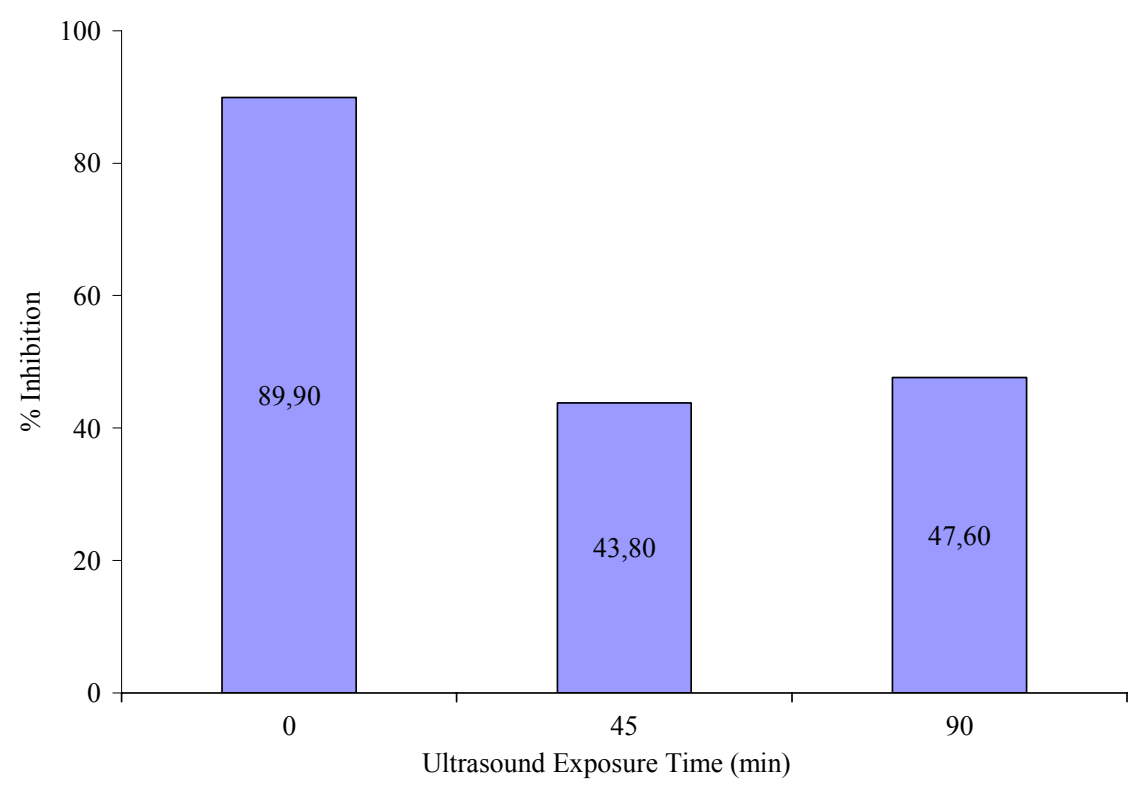

Figure 6. Effect of ultrasound on the Antioxidant Activity (AA) of extracts obtained from red-grape residues. Results are expressed as the percentage of inhibition (\%) of oxidative reaction that is achieved due to the presence of the extract. Zero ultrasound exposure time corresponds to the control extract (obtained from non treated residues).

According to above, it might be possible that the antioxidant activity of the extracted polyphenols was diminished due to the presence of other components in the extract. Further experiments using purified extracts to evaluate the antioxidant activity must be done in order to confirm this. On the other hand, it has been demonstrated that, depending on operating conditions such as frequency and power, ultrasounds do not only cause cells disruption but also molecular rearrangements that lead to either inhibition or acceleration of bio-reactions (Suslick, 1988; McClements, 1995; Sala et al., 1995; Shafiur, 2003; Capelo et al., 2005). 
Thus, our results show that, at the studied frequency and power, ultrasound treatments reduce antioxidant activity of polyphenolic extracts obtained from red-grape residues.

\section{CONCLUSIONS}

The present studio confirms that ultrasound at $35 \mathrm{kHz}$ enhances extraction of polyphenols from red-grape residues, especially at exposure times above 30min. At the studied frequency, both Total Extractive Yield (TEY) and Total Polyphenols Content (TPC) of extracts significantly $(\alpha=0.05)$ increase by increasing ultrasound exposure time, being the highest performances at 45 and $90 \mathrm{~min}$. However, at the studied conditions, ultrasound seems to affect antioxidant activity of the extracts by about $50 \%$ when compared to the antioxidant activity of extracts obtained from non sonicated residues. Our results demonstrate demonstrated that extraction of bioactive components from biological materials is improved when ultrasonic waves are applied. However, further studies at different frequencies and ultrasound power must be done in order to improve the antioxidant capacity of the polyphenols extract obtained by ultrasound-assisted extraction.

\section{REFERENCES}

Álvarez, J. La viña, la vid y el vino. (1991). Ed. Trillas. México. p. 50.

Anderson, N. (2004). http://www.foodnavigator.com/news/news-NG.asp?id=48812. 10/10/05.

Arruda, S. C. C., Rodriguez, A.P.M., and Arruda, M. A. Z. (2003). Journal of the Brazilian Chemical Society. 14 (3): 470.

Banjoo, D. R., and Nelson, P. K. (2005). Journal of Chromatography A. 1066 (1-2): 9.

Capelo, J. L., Maduro, C., and Vilhena, C. (2005). Ultrasonics Sonochemistry. 12 (3): 225.

Chemat, S., Lagha, A., AitAmar, H., Bartels, P. V., and Chemat, F. 2004. Flavour and Fragrance Journal. 19: 188.

Cieślik, E., Gręda, A., and Adamus, W. (2006). Food Chemistry. 94 (1): 135.

Cork, S. J., and Krockenberger, A. K. (1991). J. Chem. Ecol. 17: 123.

Escribano-Bailón, T., Gutierrez-Fernandez, Y., Rivas-Gonzalo, J., and Santos-Buelga, C. (1992). J. Agric. Food Chem. 40: 1794.

Fuleki, T., and da Silva, J. M. R. (1997). J. Agric. Food Chem. 45: 1156.

Gómez-Cordovés, G., Suárez, R., Bartolomé, B., and Suárez Lepe, J. A. (2003). Alimentación, Equipos y Tecnología. 22 (185): 71.

Gu, X., Cai, J., Zhu, X., and Su, Q. (2005). Journal of Separation Science. 28 (18): 2477.

Gutiérrez, A. (2002). Revista Cubana Aliment. Nutr. 16 (2): 134.

Herrera, M. C., and Luque de Castro, M. D. (2005). Journal of Chromatography A. 1100 (1): 1.

Kallithraka, S., Bakker, J., and Clifford, M. N. (1997). J. Agric. Food Chem. 45: 2211.

Kaur, C., and Kapoor, H. C. (2002). International Journal of Food Science and Technology. 37: 153.

Knorr, D., Zenker, M., Heinz, V., and Lee, D. (2004). Trends in Food Science and Technology. 15 (5): 261. 
Li, H., Pordesimo, L., and Weiss, J. (2004). Food Research International. 37: 731.

Louli, V., Ragoussis, N., and Magoulas, K. (2004). Bioresource Technology. 92 (2): 201.

Mason, T. J., Paniwnyk, L., and Lorimer, J. P. (1996). Ultrasonics Sonochemistry. 3 (3): 253.

McClements, D. J. (1995). Trends in Food Science and Tecnology. 6 (9): 293.

Medina, I. Tombo, I., Satué, M. T, German, J. B., and Frankel. E. (2002). J. Agric. Food. Chem. 50 (8): 2392.

Minami, H., Honjyo, T., and Atsuya, (1996). Spectrochimica Acta Part B: Atomic Spectroscopy. 51 (2): 211.

Moure, A., Cruz, J. M., Franco, D., Domínguez, J. M., Sineiro, J., Domínguez, H., Núñez, M. J., and Parajó, C. (2001). Food Chemistry. 72 (2): 145.

Nascentes, C., Korn, M., and Arruda, M. A. Z. (2001). Microchemical Journal. 69 (1): 37.

Pérez, R. M., Vargas, R., Martínez, F. J., García, E. V., and Hernández, B. (2003). Ars Pharmaceutica. 44 (1): 5.

Pinelo, M. (2004). Doctoral Thesis. Universidad de Santiago de Compostela. Escuela Técnica Superior de Ingeniería. $264 \mathrm{pp}$.

Prodanov, M., and Cobo, R. (2004). Alimentación, Equipos y Tecnología. 23 (186): 97.

Prodanov, M., García, C., Lucendo, C., Alonso, G. L., and Luque, S. (2005). Alimentación, Equipos y Tecnología. 24 (197): 91.

Sala, F. J. (1995). Effect of Heat and Ultrasound on Microorganisms and Enzymes. In: New Methods of Food Preservation. Ed. Gould, G. W. Chapman \& Hall, Gran Bretaña. p.p. 176204.

Shafiur, M. (2003). Manual de conservación de los alimentos. Luz y Sonido. In: La Conservación de los Alimentos. Ed. Acribia.ZZaragoza, España. p. 707-725.

Shi, J., Yu, J., Pohorly, J. E., and Kakuda, Y. (2003). Journal of Medicinal Food. 6 (4): 291.

Simal, S., Benedito, J., Sánchez, E .S., and Rosselló, C. (1998). Journal of Food Engineering. $36(3): 323$.

Singleton, V. L., and Rossi, J. A. (1965) . American Journal of Enology Viticulture. 16: 144.

Suslick, K. (1988). Ultrasound: Its chemical, physical and biological effects. In: Industrial Applications of Ultrasound. VCH Publishers. New York, USA. Pp: 97-122.

Toma, M., Vinatoru, M., Paniwnyk, L., and Mason, T. J. (2001).Ultrasonics Sonochemistry. 8: 137 .

Vernhet, A., Pellerin, P., Prieur, C., Osmianski, J., and Moutounet, M. (1996). Am. J. Enol. Vitic. 47: 25.

Vinatoru, M., Toma, M., and Mason, T. J. (1999). Advances in Sonochemistry. 5: 209.

Wang, L., and Weller, C. L. (2006). Trends in Food Science and Technology. 17 (6): 300.

Yebra, M. C., and Moreno, A. (2002). Journal of Analytical Atomic Spectrometry. 17 (10): 1425. 